\title{
Intraosseous access can be taught to medical students using the four-step approach
}

\author{
Monika Afzali ${ }^{1,2^{*}}$, Ask Daffy Kvisselgaard ${ }^{3}$, Tobias Stenbjerg Lyngeraa ${ }^{4}$ and Sandra Viggers ${ }^{5}$
}

\begin{abstract}
Background: The intraosseous $(\mathrm{IO})$ access is an alternative route for vascular access when peripheral intravascular catheterization cannot be obtained. In Denmark the $1 O$ access is reported as infrequently trained and used. The aim of this pilot study was to investigate if medical students can obtain competencies in 10 access when taught by a modified Walker and Peyton's four-step approach.

Methods: Nineteen students attended a human cadaver course in emergency procedures. A lecture was followed by a workshop. Fifteen students were presented with a case where $I O$ access was indicated and their performance was evaluated by an objective structured clinical examination (OSCE) and rated using a weighted checklist. To evaluate the validity of the checklist, three raters rated performance and Cohen's kappa was performed to assess inter-rater reliability (IRR). To examine the strength of the overall IRR, Randolph's free-marginal multi rater kappa was used.

Results: A maximum score of 15 points was obtained by nine (60\%) of the participants and two participants (13\%) scored 13 points with all three raters. Only one participant failed more than one item on the checklist. The expert rater rated lower with a mean score of 14.2 versus the non-expert raters with mean 14.6 and 14.3. The overall IRR calculated with Randolph's free-marginal multi rater kappa was 0.71.
\end{abstract}

Conclusion: The essentials of the $\mathrm{IO}$ access procedure can be taught to medical students using a modified version of the Walker and Peyton's four-step approach and the checklist used was found reliable.

Keywords: Intraosseous access, Vascular access, Medical students, Medical education, Anaesthesiology, Traumatology, Emergency medicine, Resuscitation, OSCE and checklist validity

\section{Background}

Life-threatening emergencies with intravascular volume depletion, shock or cardiac arrest make peripheral venous access difficult. To ensure adequate resuscitation, alternative methods to obtain access to the venous system can be necessary.

Central venous catheter (CVC) and intraosseous (IO) cannulation can be used as an alternative to obtain vascular access in critically ill patients. These methods are suitable for the administration of fluids, blood products,

\footnotetext{
* Correspondence: monika.afzali@regionh.dk

${ }^{1}$ Department of Anaesthesiology, University Hospital of Copenhagen, Herlev, Denmark

${ }^{2}$ Cochrane Anaesthesia, Critical and Emergency Care, The Cochrane Collaboration, Herlev, Denmark

Full list of author information is available at the end of the article
}

and medications $[1,2]$. Insertion of a CVC requires a high level of competence and can be time-consuming and difficult during resuscitation [3, 4]. The IO access has been shown to be easier to perform than peripheral venous catheter (PVC) insertion [5]. The IO needle insertion has few associated risks, a high operator satisfaction and a high rate of success even for the inexperienced clinician [3, 6-10]. Furthermore, substances injected by the IO route achieve adequate plasma concentrations in a time comparable with vascular access [11-14].

The American Heart Association (AHA) and the European Resuscitation Council (ERC) both recommend the use of IO access in cardiac arrest if PVC is not accessible $[15,16]$. Recommendations from ERC in both paediatric and adult resuscitation are to establish an IO 
access if PVC cannot be achieved within one and two minutes respectively $[15,17]$. There are no absolute contraindications for establishing the IO access as it is used on vital indication and complications such as infection and compartment syndrome are rare [3, 6-8, 18-20].

In Denmark a battery-powered IO driver $\left(\mathrm{EZ}^{\left.-\mathrm{IO}^{\circ}\right)}\right.$ is the most commonly available device in the Danish emergency departments (EDs). A Danish study showed that in 2010 the IO device was available in $74 \%$ of the EDs. However, only $11 \%$ consistently established IO access on relevant indication and prior training in the establishment of IO access had not been provided in $47 \%$ of the EDs [21].

Procedural skills in Danish medical schools are traditionally taught during clinical rotations and in skill labs. Theoretical teaching or practical training in the use of the IO devices is however not a part of the curriculum. Most medical students and junior doctors have limited experience with the IO devices and a lack of introduction and training is a possible reason for the limited use in the Danish EDs.

The aim of this pilot study was to investigate if medical students can obtain competencies in IO needle insertion in human cadavers when taught by a modified Walker and Peyton's four-step approach evaluated by an objective structured clinical examination (OSCE).

\section{Methods}

In November 2013 Students' Society of Anaesthesiology and Traumatology (SATS) at the University of Copenhagen $(\mathrm{UCPH})$ conducted a four-hour human cadaver course in emergency procedures. Nineteen medical students, all members of SATS, participated [22]. The emergency procedures taught included emergency cricothyroidotomy, decompression of tension pneumothorax, chest tube insertion, and IO needle insertion. To participate in the course, students were required to have passed the 3rd semester of medical school studies at $\mathrm{UCPH}$, which includes the anatomy dissection course. Pre-course material including a scientific paper describing the IO access technique, indications, and complications was sent to the participants prior to the course [19].

At the beginning of the course there was a $30-\mathrm{min}$ lecture regarding the indications and contraindications of the IO access presented by a registrar in anaesthesiology. This session was followed by a one-hour workshop. The workshop was carried out using a modified version of Walker and Peyton's four-step approach as the teaching method [23, 24]. The modified four-step approach consists of four phases. An initial "Demonstration" phase where participants observe while the instructor performs an IO needle insertion, just as it would be performed in real life and real time. Secondly, a "Deconstruction" phase where the instructor performs the task slowly while verbally breaking the performance down into simple steps (Table 1). The third phase is the "Formulation" where the instructor performs the task while being "talked through it" by the participants step-by-step. Finally, in the fourth "Performance" phase the participants perform the task themselves while the instructor gives the participants immediate feedback. The participants were allowed to repeat step four and practice the skill until they felt confident with the procedure.

After the course, the participants' competencies in IO needle insertion were evaluated. An OSCE was chosen as the test modality for skill evaluation [25]. Participants were presented with a case where IO access was indicated (Table 2). All necessary equipment was made available and the proximal tibia of the human cadaver was exposed (Fig. 1). For the OSCE, an earlier validated weighted checklist for manual IO cannulation was modified by the authors (SV and TL) [26, 27]. They identified nine steps as important for successful achievement of an IO access with a battery-powered IO driver (Table 1). These steps inspired to a new checklist (Table 3). Weighted points were awarded for the task being performed correctly otherwise zero points were assigned. The checklist allowed a maximum score of 15 points (Table 3).

As the participants performed the procedure, the three authors AK (rater one), MA (rater two) and TL (rater three) independently rated the performance using the weighted checklist. Consequently, each participant had three checklists assessing their performance. Rater one (R1) was a second year medical student, rater two (R2) was a sixth year medical student and rater three (R3) was a registrar in anaesthesiology. The two raters R1 and R2 were considered non-expert raters and R3 was considered the expert rater.

Statistics were performed using IBM SPSS statistics for MAC version 22.0. Armok, NY: IBM corp. Cohen's kappa was performed to assess the inter-rater reliability (IRR) between the non-expert raters and the expert rater [27, 28]. To examine the strength of the overall IRR, Randolph's free-marginal multi rater kappa was used to evaluate the validity of the checklist [28-30].

\section{Results}

Out of the 19 students who participated in the course 15 (79\%) participated in the final OSCE. Nine out of the 15 participants $(60 \%)$ obtained a total score of the maximum 15 points and two participants (13\%) scored 13 points with all three raters. For the remaining four participants there was non-agreement among the raters with a participant median score of 14.5 (range 10-15).

The two participants who scored 13 points with all three raters both failed one assessment point on the checklist. The failed assessment points were respectively; 
Table 1 Important steps for achieving intraosseous access

\begin{tabular}{ll}
\hline Task No. & Procedure Description \\
\hline 1 & Identify insertion site. Two fingers down from the tibial tuberosity and one finger medially. \\
3 & Prepare the insertion site with antiseptic swab. \\
4 & Attach needle to the driver and prime the connector. \\
5 & Align needle almost perpendicular to the bone with $10-15^{\circ}$ angulation away from knee joint. \\
6 & Insert the needle through the skin without drilling until firm contact with bone. Verify correct \\
7 & $\begin{array}{l}\text { needle size by visual inspection of markings on needle above skin level. } \\
\text { continuously until loss or decrease in resistance. }\end{array}$ \\
9 & $\begin{array}{l}\text { Stop drilling when feeling loss of resistance and steady the needle with one hand while } \\
\text { removing upper part of needle and attaching connector. }\end{array}$ \\
& Secure needle and connector properly using stabilizer. \\
& Verify correct placement by aspiration of blood and administration a saline flush without signs of extravasation.
\end{tabular}

"Infusion of $0.9 \% \mathrm{NaCl}$ " and "Fluid aspiration from marrow cavity with an empty syringe".

In four participants there was non-agreement among the raters. Three out of four had non-agreement on a single assessment point "insertion technique (drilling)", "securing the line" or "location of puncture site", respectively. Only one participant failed more than one item on the checklist and led to non-agreement on two assessment points; "insertion technique (drilling)" and "location of puncture site". On both assessment points for this participant, all raters had made comments on the checklists related to the execution of the tasks.

In two out of the five incidents of non-agreement on assessment points, there was discrepancy between expert and non-expert raters. The expert rater R3 rated lower with a mean score of 14.2 (CI: \pm 0.72 |13.48;14.92|) versus the non-expert raters with $\mathrm{R} 1$ mean score 14.6 (CI: $\pm 0.41|14.19 ; 15.00|)$ and R2 14.3. (CI: \pm 0.65 |13.65;14.95|) The IRR between the non-expert rater R1 and the expert rater R3 was 0.66 showing a substantial level of agreement and IRR between R2 and R3 was 0.59 showing a moderate level of agreement. The level of agreement between the two non-expert raters R1 and R2 was 0.56 - also showing a moderate level of agreement. The overall IRR calculated with Randolph's freemarginal multi rater kappa was 0.71 indicating a substantial level of agreement between the three raters.

Table 2 A case where 10 access is indicated

\footnotetext{
"You have been called to the emergency room where a patient is unconscious. During the primary survey you establish the need for a vascular access to initiate resuscitation with fluids and medications. Failure to gain access with a peripheral venous catheter calls for the use of the intraosseous device.

The equipment needed is placed on the table in front of you. Feel free to talk out loud while performing the procedure, however this is not a requirement."
}

\section{Discussion}

The essentials of the IO access procedure can be taught to medical students as part of a four-hour human cadaver course using a modified version of the Walker and Peyton's four-step approach. A modified version of a previously validated checklist to assess the performances of 15 medical students in gaining IO access was used. This resulted in $60 \%(n=9)$ of the participants obtaining the highest attainable points with all three raters. The checklist for assessing and evaluating performance of achieving IO access in human cadavers was found reliable with a free-marginal kappa value of 0.71 . This implied a substantial overall IRR. However, the interpretation of a multi-rater kappa must be made with caution in small study populations. The IRR between the nonexpert and expert raters showed that peer-assessment might be problematic compared to assessment performed by a more experienced clinician. Raters jointly observing and discussing a case of good performance and poor performance and agreeing on a score may ensure more uniform rating of performance in the future. Training of raters beforehand may also decrease the likelihood of guessing and further increase IRR for both non-expert and expert raters [29].

The four-step teaching approach by Walker and Peyton is a well-established method in teaching surgical procedures and PVC and its implementation for procedural skill teaching is recommended [23, 24, 31]. The approach is developed for 1:1 teaching but students also welcome it for small group training [24]. The use of this teaching method at a cadaver course may increase focus on making use of this teaching method when teaching medical students and other novice learners practical skills outside the simulation centre or skill lab. However, when evaluating the modified four-step approach used in this study, one must be aware that the teaching outcome could have been increased because of a final 


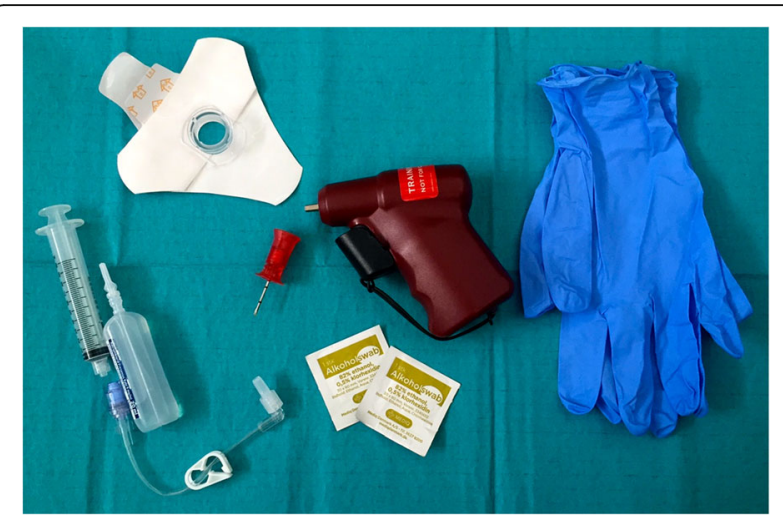

Fig. 1 The necessary equipment for the $I O$ procedure

Table 3 Checklist for the intraosseous access workshop

\begin{tabular}{|c|c|}
\hline \multicolumn{2}{|l|}{ Topical antiseptic } \\
\hline Not used & 0 \\
\hline Used on the puncture site & 1 \\
\hline \multicolumn{2}{|l|}{ Gloves } \\
\hline Not used & 0 \\
\hline Gloves used & 1 \\
\hline \multicolumn{2}{|l|}{ Insertion technique } \\
\hline Skin penetration with needle while drilling & 0 \\
\hline $\begin{array}{l}\text { Skin penetration with needle placed on the machine } \\
\text { without drilling }\end{array}$ & 1 \\
\hline $\begin{array}{l}\text { Further insertion of } \mathrm{IO} \text { needle with discontinued drilling } \\
\text { until loss of resistance }\end{array}$ & 0 \\
\hline $\begin{array}{l}\text { Further insertion of } 10 \text { needle with continuous drilling } \\
\text { until loss of resistance }\end{array}$ & 2 \\
\hline \multicolumn{2}{|l|}{ Fluid aspiration from marrow cavity with an empty syringe } \\
\hline Absence of aspiration & 0 \\
\hline Aspiration of fluid & 2 \\
\hline \multicolumn{2}{|l|}{ Infusion of $0,9 \% \mathrm{NaCl}$} \\
\hline Absence of infusion of $0,9 \% \mathrm{NaCl}$ & 0 \\
\hline Infusion of $0,9 \% \mathrm{NaCl}$ & 2 \\
\hline \multicolumn{2}{|l|}{ Securing the line } \\
\hline No further securing of $I O$ line & 0 \\
\hline $\begin{array}{l}\text { Use of dedicated stabilizer and/or other fixation to secure } \\
\text { the line }\end{array}$ & 1 \\
\hline \multicolumn{2}{|l|}{ Location of the puncture site (observed after insertion) } \\
\hline Outside the puncture site or mobile needle & 0 \\
\hline On the puncture site $+/-0,5 \mathrm{~cm}$ & 3 \\
\hline \multicolumn{2}{|l|}{ Angle of insertion (observed after insertion) } \\
\hline Oblique insertion & 0 \\
\hline Perpendicular insertion $+/-10^{\circ}$ & 2 \\
\hline \multicolumn{2}{|l|}{ Total Score } \\
\hline \multirow[t]{2}{*}{1.0 access functioning } & Yes_ \\
\hline & No_ \\
\hline
\end{tabular}

OSCE, as testing has been shown to increase skill learning [32].

No minimal score was set as a value for passing or failing the checklist in this study. The previously validated checklist for manual IO cannulation used a score above 15 out of 20 possible points $(>75 \%)$ as sufficient for passing - even if some of the highest weighted points on the checklist were failed [24]. If this were to be applied in our study a score of 12 points would be sufficient to pass. Using this as a pass value retrospectively all students in this study would have passed based on the median scores, whereas one would have failed based on the expert rater's score. Deciding on a minimal score and the use of essential points that are not to be failed should be implemented to ensure adequate power of the checklist in distinguishing between failed and successful IO-placement. Furthermore, addition of time to IO insertion and time spent on insertion should be included if the checklist is to be used for assessment of skill proficiency in a live patient population.

Failure to achieve IO access is related to technical difficulties or failure to locate correct insertion site [18]. This underlines the importance of training and assessment of those who will perform the procedure. In Denmark IO access is taught at courses such as European Paediatric Life Support and Advanced Trauma Life Support but the use in the clinical setting remains infrequent [19]. Teaching students how to obtain an IO access during medical school may result in more frequent use in the future, increase competence by allowing time for spaced repetition of the skill, and improve initial resuscitation attempts and consequently patient outcome.

Development of formal training in the use of IO devices may help to ensure proper application of $\mathrm{IO}$ access when indicated according to AHA and ERC guidelines.

The proximal tibia was chosen as the insertion site for both the workshop and the final OSCE and a batterypowered IO driver device was used. Studies indicate that this device is superior to other devices as it is easy to use and holds a high success rate of insertion among users [11, 33].

The proximal tibia and the humeral head are often the preferred site of IO needle insertion [5, 8, 34]. A randomized study on 182 patients during out-of-hospital cardiac arrest shows that achieving IO access at the proximal tibia is faster and more often successful compared to either PVC insertion or IO placement in the humeral head [5]. This might be due to on-going activity around the humerus during resuscitation increasing rates of dislodgement $[5,34]$. Placement in the proximal tibia rather than the humeral head is also easier on human cadavers due to tissue preservation and comparison of flow rates shows no significant difference [8]. 


\section{Limitations}

As the OSCE was performed immediately after the workshop session the retention of the skill taught was not tested and the possibility that the test itself enhanced the learning outcome is possible [35]. Furthermore a total of four of the participants chose not to participate in the final OSCE. It was not investigated further why these participants declined the OSCE. However, this could be because they did not feel adequately prepared for being tested and their exclusion from the tested group may affect the results positively.

No demographical data about the participants were collected, however all participants had passed anatomy class, as this was a pre-requisite for participation. We assumed that participants did not have any experience with IO insertion techniques from training or clinical setting, as IO access is not part of clinical skills curriculum at UCPH medical school. Their theoretical knowledge was therefore not tested pre- or post-course as it was expected that the participants' knowledge would increase no matter what teaching approach was being used.

\section{Conclusion}

This study demonstrates that within a four-hour time frame the fundamentals of achieving an IO access can be taught to medical students through a human cadaver course using Walker and Peyton's' four-step approach as the teaching method. Assessment using a checklist can be a reliable way to assess the students but for future implementation we recommend raters with prior education in the checklist, a crossover design as well as testing different learning modalities against each other. To ensure retention of the gained knowledge we suggest repetitive training in achieving IO access to be integrated as a part of medical school's clinical skills curriculum to ensure the highest standard of care in emergency situations and to maximize skill retention.

\section{Abbreviations}

AHA: American Heart Association; CVC: Central venous catheter

ED: Emergency department; ERC: European Resuscitation Council; IO: Intraosseous; IRR: Inter-rater-reliability; OSCE: Objective structured clinical examination; PVC: Peripheral venous catheter; R1: Rater one; R2: Rater two; R3: Rater three; UCPH: University of Copenhagen

\section{Acknowledgements}

Panum Institute for the donation of human cadavers.

\section{Funding}

None.

\section{Availability of data and materials}

The datasets generated and/or analysed during the current study are available from the corresponding author on reasonable request.

\section{Authors' contributions}

All authors have made substantial contributions to all of the following: the conception and design of the study, acquisition of data, analysis and interpretation of data, drafting the manuscript, revised it critically for important intellectual content and finally approved the version to be submitted. There is no overlap with previous publications and we confirm that the manuscript, including related data, figures and tables, has not been published previously and the manuscript is not under consideration elsewhere. All authors agreed to be accountable for all aspects of the work in ensuring that questions related to the accuracy and integrity of any part of the work are appropriately investigated and resolved.

\section{Competing interests}

The authors declare that they have no competing interests.

\section{Consent for publication}

Not applicable.

\section{Ethics approval and consent to participate}

All participants gave verbal and written informed consent about their participation and were informed of their right to decline to participate, and their right to withdraw from the study at any time.

The study was conducted in the dissection hall at UCPH on deceased adults who had donated their bodies to science and education at the Department of Cellular and Molecular Medicine at UCPH in accordance with Danish legislation (Health Law no. 546, §188). The head of the Body Donation Program at the Department of Cellular and Molecular Medicine, UCPH approved the study.

\section{Author details}

${ }^{1}$ Department of Anaesthesiology, University Hospital of Copenhagen, Herlev, Denmark. ${ }^{2}$ Cochrane Anaesthesia, Critical and Emergency Care, The Cochrane Collaboration, Herlev, Denmark. ${ }^{3}$ Students' Society of Anaesthesiology \& Traumatology, Faculty of Health and Medical Sciences, University of Copenhagen, Herlev, Denmark. ${ }^{4}$ Department of Anaesthesiology, Nordsjælland Hospital, Herlev, Denmark. ${ }^{5}$ Copenhagen Academy for Medical Education and Simulation, Capital Region of Denmark, Herlev, Denmark.

Received: 19 August 2016 Accepted: 7 February 2017

Published online: 02 March 2017

\section{References}

1. Lewis $P$, Wright C. Saving the critically injured trauma patient: a retrospective analysis of 1000 uses of intraosseous access. Emerg Med J. 2015;32:463-7. Available from: http://www.ncbi.nlm.nih.gov/pubmed/24981009.

2. Glaeser PW, Hellmich TR, Szewczuga D, Losek JD, Smith DS. Five-year experience in prehospital intraosseous infusions in children and adults. Ann Emerg Med. 1993;22:1119-24. Available from: http://www.ncbi.nlm.nih.gov/ pubmed/8517560

3. Leidel BA, Kirchhoff C, Bogner V, Stegmaier J, Mutschler W, Kanz K-G, et al. Is the intraosseous access route fast and efficacious compared to conventional central venous catheterization in adult patients under resuscitation in the emergency department? A prospective observational pilot study. Patient Saf Surg. 2009;3:24. Available from: https://www.ncbi. nlm.nih.gov/pmc/articles/PMC2764565/?tool=pmcentrez.

4. Neumar RW, Otto CW, Link MS, Kronick SL, Shuster M, Callaway CW, et al. Part 8: adult advanced cardiovascular life support: 2010 American Heart Association Guidelines for Cardiopulmonary Resuscitation and Emergency Cardiovascular Care. Circulation. 2010;122:S729-67. Available from: http:// www.ncbi.nlm.nih.gov/pubmed/20956224.

5. Reades R, Studnek JR, Vandeventer S, Garrett J. Intraosseous versus intravenous vascular access during out-of-hospital cardiac arrest: a randomized controlled trial. Ann Emerg Med. 2011;58:509-16. Available from: http://www.ncbi.nlm.nih.gov/pubmed/21856044.

6. Dolister M, Miller S, Borron S, Truemper E, Shah M, Lanford MR, et al. Intraosseous vascular access is safe, effective and costs less than central venous catheters for patients in the hospital setting. J Vasc Access. 2013;14: 216-24. Available from: http://www.ncbi.nlm.nih.gov/pubmed/23283646.

7. Ngo AS-Y, Oh JJ, Chen Y, Yong D, Ong MEH. Intraosseous vascular access in adults using the EZ-IO in an emergency department. Int J Emerg Med. 2009;2:155-60. Available from: https://www.ncbi.nlm.nih.gov/pmc/articles/ PMC2760700/?tool=pmcentrez.

8. Ong MEH, Chan YH, Oh JJ, Ngo AS-Y. An observational, prospective study comparing tibial and humeral intraosseous access using the EZ-IO. Am J 
Emerg Med. 2009;27:8-15. Available from: http://www.ncbi.nlm.nih.gov/ pubmed/19041528.

9. Ong MEH, Ngo ASY, Wijaya R. An observational, prospective study to determine the ease of vascular access in adults using a novel intraosseous access device. Ann Acad Med Singapore. 2009;38:121-4. Available from: http://www.ncbi.nlm.nih.gov/pubmed/19271038.

10. Levitan RM, Bortle CD, Snyder TA, Nitsch DA, Pisaturo JT, Butler KH. Use of a battery-operated needle driver for intraosseous access by novice users: skill acquisition with cadavers. Ann Emerg Med. 2009;54:692-4. Available from: http://www.ncbi.nlm.nih.gov/pubmed/19643511.

11. Von Hoff DD, Kuhn JG, Burris HA, Miller L. Does intraosseous equal intravenous? A pharmacokinetic study. Am J Emerg Med. 2008;26:31-8. Available from: http://www.ncbi.nlm.nih.gov/pubmed/18082778.

12. Wenzel V, Lindner KH, Augenstein S, Voelckel W, Strohmenger HU, Prengel AW, et al. Intraosseous vasopressin improves coronary perfusion pressure rapidly during cardiopulmonary resuscitation in pigs. Crit Care Med. 1999;27: 1565-9. Available from: http://www.ncbi.nlm.nih.gov/pubmed/10470765.

13. Hoskins SL, do Nascimento P, Lima RM, Espana-Tenorio JM, Kramer GC. Pharmacokinetics of intraosseous and central venous drug delivery during cardiopulmonary resuscitation. Resuscitation. 2012;83:107-12. Available from: http://www.ncbi.nlm.nih.gov/pubmed/21871857.

14. Strandberg G, Larsson A, Lipcsey M, Michalek J, Eriksson M. Intraosseous and intravenous administration of antibiotics yields comparable plasma concentrations during experimental septic shock. Acta Anaesthesiol Scand. 2015;59:346-53. Available from: https://www.ncbi.nlm.nih.gov/pmc/articles/ PMC4338763/?tool=pmcentrez.

15. Soar J, Nolan JP, Böttiger BW, Perkins GD, Lott C, Carli P, et al. European Resuscitation Council Guidelines for Resuscitation 2015: Section 3. Adult advanced life support. Resuscitation. 2015;95:100-47. Available from: http:// www.ncbi.nlm.nih.gov/pubmed/26477701.

16. Kleinman ME, Brennan EE, Goldberger ZD, Swor RA, Terry M, Bobrow BJ, et al. Part 5: Adult Basic Life Support and Cardiopulmonary Resuscitation Quality: 2015 American Heart Association Guidelines Update for Cardiopulmonary Resuscitation and Emergency Cardiovascular Care. Circulation. 2015;132:S414-35. Available from: http://www.ncbi.nlm.nih.gov/ pubmed/26472993.

17. Maconochie IK, Bingham R, Eich C, López-Herce J, Rodríguez-Núñez A, Rajka T, et al. European Resuscitation Council Guidelines for Resuscitation 2015. Resuscitation. 2015;95:223-48. Available from: http://www.ncbi.nlm.nih.gov/ pubmed/26477414.

18. Santos D, Carron P-N, Yersin B, Pasquier M. EZ-IO( $\left(^{(}\right)$intraosseous device implementation in a pre-hospital emergency service: A prospective study and review of the literature. Resuscitation. 2013:84:440-5. Available from: http://www.ncbi.nlm.nih.gov/pubmed/23160104.

19. Thim T, Grove EL, Krarup NHV, Løfgren B. [Intraosseous infusion]. Ugeskr. Laeger. 2011;173:1496-8. Available from: http://www.ncbi.nlm.nih.gov/ pubmed/21627912

20. Davidoff J, Fowler R, Gordon D, Klein G, Kovar J, Lozano M, et al. Clinical evaluation of a novel intraosseous device for adults: prospective, 250patient, multi-center trial. JEMS. 2005;30:suppl 20-3. Available from: http:// www.ncbinlm.nih.gov/pubmed/16382512

21. Molin R, Hallas P, Brabrand M, Schmidt TA. Current use of intraosseous infusion in Danish emergency departments: a cross-sectional study. Scand J Trauma Resusc Emerg Med. 2010;18:37. Available from: https://www.ncbi. nlm.nih.gov/pmc/articles/PMC2904266/?tool=pmcentrez.

22. Viggers S, Olsen LL, Afzali M. Students' Society for Anaesthesiology and Traumatology. Trends Anaesth Crit Care. 2015;5:80-3. Available from: http:// linkinghub.elsevier.com/retrieve/pii/S2210844014200529.

23. Walker M, Peyton JWR. Teaching in theatre. In: Peyton JWR, editor. Teaching and learning in medical practice. Rickmansworth: Manticore Publishers Europe Ltd; 1998. p. 171-80.

24. Nikendei C, Huber J, Stiepak J, Huhn D, Lauter J, Herzog W, et al. Modification of Peyton's four-step approach for small group teaching - a descriptive study. BMC Med Educ. 2014;14:68. Available from: https://www. ncbi.nlm.nih.gov/pmc/articles/PMC3976361/?tool=pmcentrez.

25. Hastie MJ, Spellman JL, Pagano PP, Hastie J, Egan BJ. Designing and implementing the objective structured clinical examination in anesthesiology. Anesthesiology. 2014;120:196-203. Available from: http:// www.ncbi.nlm.nih.gov/pubmed/24212197.

26. Oriot D, Darrieux E, Boureau-Voultoury A, Ragot S, Scépi M. Validation of a performance assessment scale for simulated intraosseous access. Simul
Healthc. 2012;7:171-5. Available from: http://www.ncbi.nlm.nih.gov/ pubmed/22511182

27. Schmutz J, Eppich WJ, Hoffmann F, Heimberg E, Manser T. Five steps to develop checklists for evaluating clinical performance: an integrative approach. Acad Med. 2014;89:996-1005. Available from: http://www.ncbi. nlm.nih.gov/pubmed/24826862.

28. Randolph JJ. Free-Marginal Multirater Kappa (multirater K[free]): An Alternative to Fleiss' Fixed-Marginal Multirater Kappa. Online Submiss. 2005. Available from: http://eric.ed.gov/?id=ED490661.

29. McHugh ML. Interrater reliability: the kappa statistic. Biochem Medica. 2012; 22:276-82. Available from: https://www.ncbi.nlm.nih.gov/pmc/articles/ PMC3900052/?tool=pmcentrez

30. Brennan RL, Prediger DJ. Coefficient Kappa: Some Uses, Misuses, and Alternatives. Educ Psychol Meas. 1981;41:687-99. Available from: http://epm. sagepub.com/content/41/3/687.short.

31. Wang TS, Schwartz JL, Karimipour DJ, Orringer JS, Hamilton T, Johnson TM. An education theory-based method to teach a procedural skill. Arch Dermatol. 2004;140:1357-61. Available from: http://www.ncbi.nlm.nih.gov/ pubmed/15545545.

32. Kromann $C B$, Jensen $M L$, Ringsted $C$. The effect of testing on skills learning. Med Educ. 2009:43:21-7. Available from: http://www.ncbi.nlm.nih.gov/ pubmed/19140995.

33. Weiser G, Hoffmann Y, Galbraith R, Shavit I. Current advances in intraosseous infusion - a systematic review. Resuscitation. 2012;83:20-6. Available from: http://www.ncbi.nlm.nih.gov/pubmed/21871243.

34. Reades R, Studnek JR, Garrett JS, Vandeventer S, Blackwell T. Comparison of first-attempt success between tibial and humeral intraosseous insertions during out-of-hospital cardiac arrest. Prehosp Emerg Care. 2011;15:278-81. Available from: http://www.ncbi.nlm.nih.gov/pubmed/21275573.

35. Kromann CB, Bohnstedt C, Jensen ML, Ringsted C. The testing effect on skills learning might last 6 months. Adv Health Sci Educ Theory Pract. 2010; 15:395-401. Available from: http://www.ncbi.nlm.nih.gov/pubmed/ 19838814.

\section{Submit your next manuscript to BioMed Central and we will help you at every step:}

- We accept pre-submission inquiries

- Our selector tool helps you to find the most relevant journal

- We provide round the clock customer support

- Convenient online submission

- Thorough peer review

- Inclusion in PubMed and all major indexing services

- Maximum visibility for your research

Submit your manuscript at www.biomedcentral.com/submit
Biomed Central 